\title{
Pharmacokinetics of a single oral dose of vitamin D3 (70,000 IU) in pregnant and non-pregnant women
}

\author{
Daniel E Roth ${ }^{1,3^{*}}$, Abdullah Al Mahmud ${ }^{2}$, Rubhana Raqib ${ }^{2}$, Robert E Black ${ }^{1}$ and Abdullah H Baqui ${ }^{1,2}$
}

\begin{abstract}
Background: Improvements in antenatal vitamin D status may have maternal-infant health benefits. To inform the design of prenatal vitamin D3 trials, we conducted a pharmacokinetic study of single-dose vitamin D3 supplementation in women of reproductive age.
\end{abstract}

Methods: A single oral vitamin D3 dose (70,000 IU) was administered to 34 non-pregnant and 27 pregnant women (27 to 30 weeks gestation) enrolled in Dhaka, Bangladesh $\left(23^{\circ} \mathrm{N}\right)$. The primary pharmacokinetic outcome measure was the change in serum 25-hydroxyvitamin D concentration over time, estimated using model-independent pharmacokinetic parameters.

Results: Baseline mean serum 25-hydroxyvitamin D concentration was $54 \mathrm{nmol} / \mathrm{L}(95 \% \mathrm{Cl} 47,62)$ in non-pregnant participants and $39 \mathrm{nmol} / \mathrm{L}(95 \% \mathrm{Cl} 34,45)$ in pregnant women. Mean peak rise in serum 25 -hydroxyvitamin D concentration above baseline was similar in non-pregnant and pregnant women $(28 \mathrm{nmol} / \mathrm{L}$ and $32 \mathrm{nmol} / \mathrm{L}$, respectively). However, the rate of rise was slightly slower in pregnant women (i.e., lower 25 -hydroxyvitamin $D$ on day 2 and higher 25-hydroxyvitamin D on day 21 versus non-pregnant participants). Overall, average 25-hydroxyvitamin D concentration was $19 \mathrm{nmol} / \mathrm{L}$ above baseline during the first month. Supplementation did not induce hypercalcemia, and there were no supplement-related adverse events.

Conclusions: The response to a single 70,000 IU dose of vitamin D3 was similar in pregnant and non-pregnant women in Dhaka and consistent with previous studies in non-pregnant adults. These preliminary data support the further investigation of antenatal vitamin D3 regimens involving doses of $\leq 70,000 \mathrm{IU}$ in regions where maternal-infant vitamin D deficiency is common.

Trial registration: ClinicalTrials.gov (NCT00938600)

Keywords: Vitamin D, Bangladesh, Pregnancy, Pharmacokinetics

\section{Background}

Vitamin D is essential for the growth and development of the human skeleton throughout the life cycle [1]. There is considerable speculation regarding the potential effects of vitamin D on both skeletal and extra-skeletal aspects of reproductive physiology and fetal development, yet it remains unknown whether there are benefits to improving maternal antenatal vitamin D status beyond the correction

\footnotetext{
* Correspondence: daniel.roth@sickkids.ca

'Department of International Health, The Johns Hopkins Bloomberg School of Public Health, Baltimore, MD 21205, USA

${ }^{3}$ Current address: Department of Paediatrics, Hospital for Sick Children and University of Toronto, Toronto, ON, Canada

Full list of author information is available at the end of the article
}

of severe deficiency $[2,3]$. Clinical trials employing vitamin $\mathrm{D}$ dose regimens that safely optimize maternal-fetal vitamin D status will enable testing of these hypotheses [4]. However, very few studies have rigorously addressed vitamin D supplementation during pregnancy, and the single-dose vitamin D3 pregnancy trials published to date have provided little insight into pharmacokinetics or safety $[5,6]$. Moreover, there is a near complete absence of pharmacological data in South Asia, where the vitamin D status of pregnant women [7] and young infants [8] is poor in spite of the tropical climate.

The pharmacokinetics of oral vitamin D3 are conventionally described with respect to its effect on the serum 
concentration of the predominant circulating metabolite, 25-hydroxyvitamin D $([25(\mathrm{OH}) \mathrm{D}])$, which is a wellestablished biomarker of systemic vitamin D status [9]. The present study was conducted to assess changes in serum $[25(\mathrm{OH}) \mathrm{D}]$ and calcium following a single oral vitamin D3 dose (70,000 IU) in non-pregnant women and pregnant women in the third trimester of pregnancy in Dhaka, Bangladesh. The aim was to generate preliminary pharmacokinetic (PK) and safety data to inform the design of supplementation regimens for use in future larger-scale trials of antenatal vitamin D supplementation in Bangladesh.

\section{Methods}

\section{Participants}

Pregnant and non-pregnant women were enrolled at a clinic in Dhaka, Bangladesh $\left(24^{\circ} \mathrm{N}\right)$ from July 2009 to February 2010 if they were aged 18 to $<35$ years, held permanent residence in Dhaka at a fixed address, and planned to stay in Dhaka for at least four months (Figure 1). Reasons for exclusion were a known medical condition, self-reported current use of any dietary supplements containing vitamin $\mathrm{D}$, use of anti-convulsant or antimycobacterial medications, severe anemia (hemoglobin concentration $<70 \mathrm{~g} / \mathrm{L}$ ), or hypertension at enrollment (systolic blood pressure $\geq 140 \mathrm{mmHg}$ or diastolic blood pressure $\geq 90 \mathrm{mmHg}$ on at least two measurements). Pregnant women were excluded if they had major risk factors for preterm delivery (e.g., preterm labor or previous preterm delivery), pregnancy complications or had previously delivered an infant with a congenital anomaly or perinatal death. Non-pregnant women were excluded if they were possibly pregnant (e.g., missed recent menses) or lactating.

All participants in this study received a dose of vitamin D (70,000 IU) at baseline. Primary PK analyses involved participants who did not receive any additional vitamin D throughout follow-up ("single-dose group"). However, to enhance the assessment of 25(OH)D response and safety during the first week of follow-up, an additional cohort of participants who continued to receive weekly vitamin D doses beginning on day 7 ("weekly-dose group") contributed biochemical data to the present analysis for the first 7 days after the 70,000 IU dose (i.e., up to the time preceding their 2nd dose). Findings related to the effect of weekly dosing will be reported elsewhere. Participants were enrolled in stages according to a design that enabled interim analyses and the testing of supplementation regimens in non-pregnant participants prior to their initiation in pregnant women: non-pregnant participants were enrolled in the summer (July to September 2009); pregnant women who received only a single dose were enrolled during the 30th week of gestation in August-September 2009; and, pregnant participants who received the initial dose followed by weekly doses were enrolled at 27 to $<31$ completed weeks of gestation in February 2010. The study was reviewed and approved by the Institutional Review Board at The Johns Hopkins Bloomberg School of Public Health

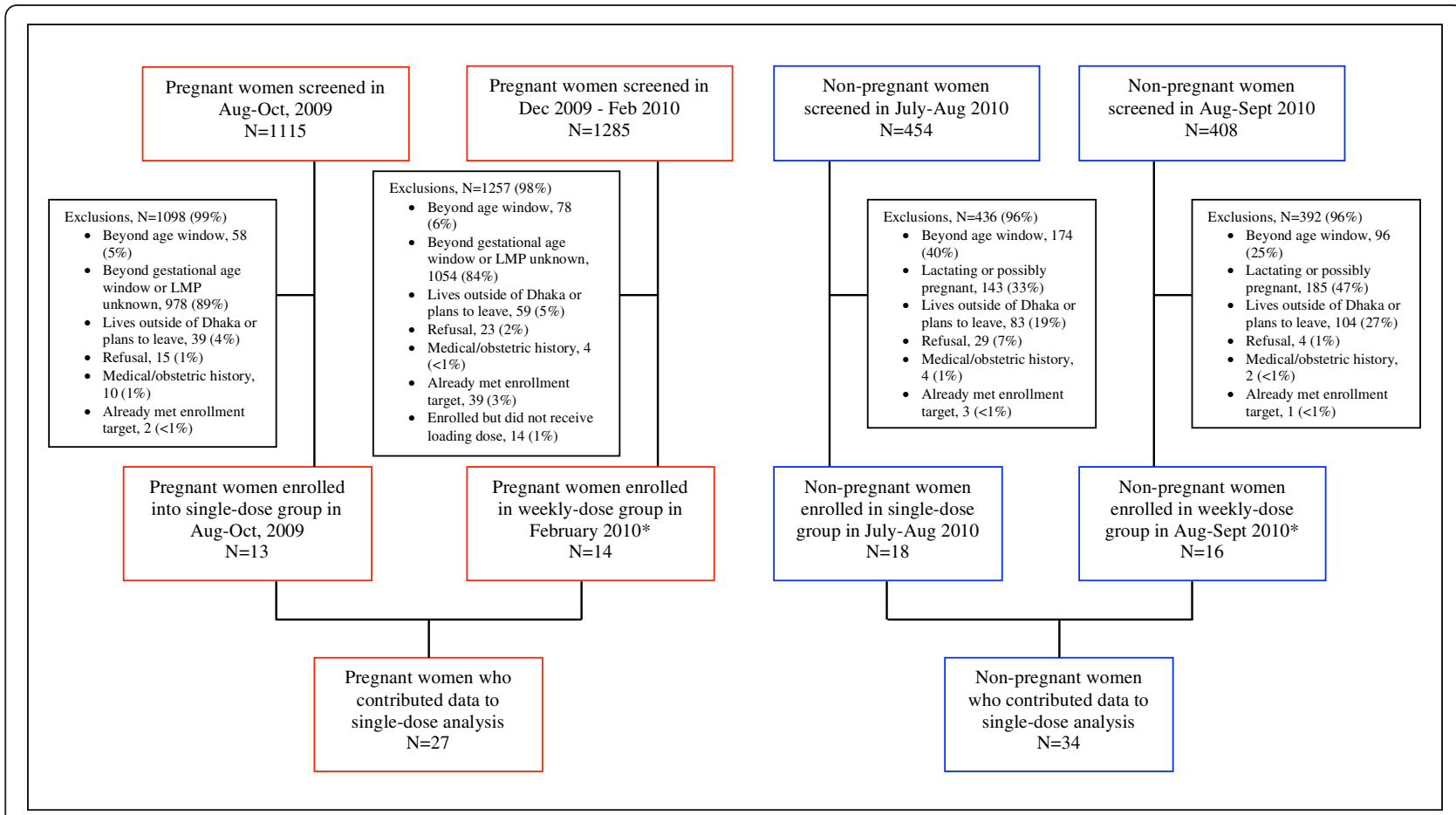

Figure 1 Flow diagram of participant screening, exclusions, and enrollment. 
and the International Center for Diarrheal Disease Research, Bangladesh (ICDDR,B). All participants gave signed informed consent prior to participation. The trial was registered at ClinicalTrials.gov (NCT00938600).

\section{Intervention}

Vitamin D3 (cholecalciferol) 70,000 IU (1.75 mg) was administered directly by study personnel. The dose was selected to be intermediate between the doses previously studied in the only two rigorous single-dose vitamin D3 pharmacokinetic studies published at the time our study was designed (50,000 [10] and 100,000 IU [11]), thus providing reassurance in terms of probable safety as well as enabling coherent between-study comparisons. The vitamin D3 supplement (Vigantol Oil, Merck KGaA, Germany) was a liquid formulation (20,000 IU D3/mL). The batch of Vigantol Oil used in the study had a concentration of 20,697 IU/mL according to the manufacturer's certificate of analysis (May, 2009). The stability of the vitamin D3 was established by independent testing of unused Vigantol Oil at the end of the study (June 2010) in the laboratory of Dr. Reinhold Vieth [12], which revealed a concentration of $19,300 \mathrm{IU} / \mathrm{mL}$ (96.5\% of the labeled concentration). Participants were advised not to take other vitamin D-containing supplements during the study period, but were permitted to take other micronutrient supplements (including calcium). All pregnant participants were provided standard iron and folic acid supplementation.

\section{Follow-up}

Study personnel assessed participants at least weekly. Nonpregnant participants who received only the single dose participated in weekly follow-up for 10 weeks; pregnant women in the single-dose group were assessed at least weekly until delivery, and then at least three times between delivery and discharge from the study at one-month postpartum. Visits involved a checklist of symptoms related to hypo- and hypercalcemia (decreased appetite, weight loss, vomiting, fever or chills, constipation, abdominal pain, excessive thirst, frequent urination, muscle weakness, back, arm, or leg pain, confusion, or depression), blood pressure measurement, and confirmation of fetal viability.
Abnormal urinalyses, hypertension, reported severe symptoms, or persistence of any mild symptomatic complaints (i.e., decreased appetite, weight loss, vomiting, fever or chills, constipation, abdominal pain, excessive thirst, frequent urination, muscle weakness, back, arm, or leg pain, confusion, or depression) for two consecutive visits prompted referral to the study physician for further evaluation. Participants were referred to an antenatal care physician at the maternity clinic for treatment of urinary tract infections, hypertension, or other medical problems that arose. Participants with obstetric complications were transported to a local tertiary-care hospital with advanced neonatal care facilities. All costs of medical and obstetric care were borne by the study.

\section{Specimen collection and biochemical analyses}

Participants provided up to six scheduled blood specimens and at least seven urine samples during the 10-week follow-up period beginning on the day of supplement administration (Figure 2). To limit the burden of specimen collection on each individual, yet still enable robust grouplevel pharmacokinetic and safety analyses, participants were assigned to one of two sampling schedules (A or B) to enhance coverage of the follow-up period (Figure 2). During the first week, specimens were collected at baseline and then additionally on either day 2 or 4 to monitor for possible early transient elevations in serum calcium and to minimize the chance of missing a possible early peak in $[25(\mathrm{OH}) \mathrm{D}]$. In the single-dose only groups, blood collection thereafter was scheduled predominantly in the first month because this was when the peak [25(OH)D] [11] and the highest risk of hypercalcemia were anticipated. In pregnant women in the single-dose only group, the specimen collection schedule was continued in the postpartum period if delivery occurred prior to 10 weeks from enrollment. In pregnant participants, venous cord blood samples were collected immediately following delivery of the placenta.

Serum samples (separated from maternal venous and umbilical vein blood) and random spot urine specimens were maintained at $+4^{\circ} \mathrm{C}$ prior to same-day transfer to the laboratory. Sera were frozen at $-20^{\circ} \mathrm{C}$. Aliquots for the 25 $(\mathrm{OH}) \mathrm{D}$ assay were shipped at ambient temperature from

\begin{tabular}{|c|c|c|c|c|c|c|c|c|c|c|c|c|c|c|c|c|}
\hline & & \multicolumn{15}{|c|}{ Day } \\
\hline & & 0 & 2 & 4 & 7 & 14 & 21 & 28 & 35 & 42 & 49 & 56 & 63 & 65 & 67 & 70 \\
\hline \multirow{2}{*}{$\begin{array}{c}\text { Single-dose } \\
\text { groups }\end{array}$} & $\mathbf{A}$ & 0 & 0 & & 0 & घ & 0 & घ & 0 & a & - & 0 & घ & & & $\square$ \\
\hline & B & $0 \square$ & 0 & & (1) & 0 & (1) & 0 & 口 & 0 & - & 口 & $\bar{\square}$ & & & 0 \\
\hline \multirow{2}{*}{$\begin{array}{l}\text { Weekly-dose } \\
\text { groups }\end{array}$} & C & $0 \square$ & & 0 & 0 & & & & & & & & & & & \\
\hline & D & $0 \square$ & & 0 & घ & & & & & & & & & & & \\
\hline
\end{tabular}

Figure 2 Blood and urine specimen collection schedules. Participants in "single-dose only" groups were randomized to one of two schedules (A or B) of specimen collection over a period 70 days. Participants in the "weekly dose" groups were similarly randomized to one of two schedules ( $C$ or D); however, the analysis of single-dose pharmacokinetics only included those specimens collected up to and including day 7 , preceding administration of the 2nd vitamin D dose. 
Dhaka to Toronto $(25(\mathrm{OH}) \mathrm{D}$ is stable under a range of conditions). Total serum [25(OH)D] was measured with the Diasorin Liaison Total assay in the laboratory of Dr. Reinhold Vieth (Mount Sinai Hospital, Toronto) according to a method previously described [13]. This laboratory participates in and meets the performance targets of the International Vitamin D External Quality Assessment Scheme [14]. Mean within-run coefficient of variation (CV\%) was $7.8 \%$ (5.8\% for specimens with values $<150 \mathrm{nmol} / \mathrm{L}$ ) and mean between-run CV\% was 10.5\% (9.0\% for specimens $<150 \mathrm{nmol} / \mathrm{L}$ ). Ancillary serum and urine biochemical tests were performed using the AU640 Olympus Autoanalyzer (Olympus Corporation, Japan) at ICDDR,B.

The primary pharmacokinetic (PK) outcome measure was the serum $[25(\mathrm{OH}) \mathrm{D}]$; incremental changes from baseline $(\Delta[25(\mathrm{OH}) \mathrm{D}])$ were calculated as an individual's absolute $[25(\mathrm{OH}) \mathrm{D}]$ at each visit minus her baseline [25 $(\mathrm{OH}) \mathrm{D}]$. The primary safety-related outcome was maternal albumin-adjusted serum calcium concentration ([Ca]), calculated using a conventional formula: $[\mathrm{Ca}]+(0.02 \%$ (40-albumin)). The reference range for albumin-adjusted serum calcium was set at $2.10-2.60 \mathrm{mmol} / \mathrm{L}$, the upper limit of which was a conservative threshold relative to those used by: the local laboratory in Dhaka (2.62 $\mathrm{mmol} / \mathrm{L})$, the US Institute of Medicine (IOM) 1997 dietary reference intakes (DRIs) for vitamin D (2.75 mmol/L) [15], and the IOM revised 2011 vitamin D DRIs (2.63 mmol/L) [1]. An albumin-adjusted serum calcium concentration $>2.60 \mathrm{mmol} / \mathrm{L}$ prompted a repeat measurement on a new specimen as soon as possible. Confirmed hypercalcemia was a priori defined as albumin-adjusted serum calcium concentration $>2.60$ $\mathrm{mmol} / \mathrm{L}$ on both specimens, since hypercalcemia caused by vitamin $\mathrm{D}$ intoxication would not be expected to resolve within a few days without intervention.

The urinary calcium:creatinine ratio (ca:cr) was expressed as $\mathrm{mmol} \mathrm{Ca} / \mathrm{mmol} \mathrm{Cr}$, and 1.0 was considered the nominal upper limit of the reference range [16]. Any episode of urinary ca:cr $>1.0 \mathrm{mmol} / \mathrm{mmol}$ prompted a repeat urine ca: cr measurement within one week. In addition, a ca:cr > $0.85 \mathrm{mmol} / \mathrm{mmol}$ that was also a 2 -fold or greater increase over the lowest previously observed ratio in the same participant prompted repeat urine assessment. Persistent hypercalciuria was defined as ca:cr $>1.0 \mathrm{mmol} / \mathrm{mmol}$ on two consecutive tests, or on two non-consecutive measurements that occurred in the presence of persistent symptoms suggestive of possible hypercalcemia. Persistent hypercalciuria or persistent ca: $\mathrm{cr}>0.85 \mathrm{mmol} / \mathrm{mmol}$ (under the conditions listed above) were indications for unscheduled measurement of serum calcium.

\section{Statistical analyses}

Continuous outcome variables were described by means, standard deviations (SD), and 95\% confidence intervals
(95\% CI). Non-normally distributed variables (including [25(OH)D]) were described by geometric means with 95\% CI's, medians and interquartile ranges (IQR), and were log-transformed for modeling. In the primary PK analysis, the following model-independent PK parameters were estimated for each individual in the singledose only groups $(\mathrm{N}=31): 1)$ maximum observed [25 $(\mathrm{OH}) \mathrm{D}](\mathrm{Cmax})$; 2) maximum observed $\Delta[25(\mathrm{OH}) \mathrm{D}]$ above baseline $(\Delta \mathrm{Cmax})$; 3$)$ timing of $\mathrm{Cmax}$ in days (Tmax); and 4) area under the $\Delta[25(\mathrm{OH}) \mathrm{D}]$-time curve (AUC), which was interpreted as a global measure of vitamin D3 bioavailability. Individual participants' AUCs were estimated manually by the trapezoidal method, and negative $\Delta[25(\mathrm{OH}) \mathrm{D}]$ values were zeroed so that the AUC represented the positive area above baseline. AUC was estimated for the first month to enable comparisons to other published PK studies [10,11]. $\mathrm{AUC}_{28 / 35}$ was calculated for either 0 to 28 days or 0 to 35 days, depending on the timing of the blood sampling (Figure 2); similarly, $\mathrm{AUC}_{56 / 70}$ was calculated for the period 0 to 56 days or 0 to 70 days. An individual's average $\Delta[25(\mathrm{OH})$ D] during the first 28 days $\left(\Delta \operatorname{Cavg}_{28}\right)$ was calculated by dividing $\mathrm{AUC}_{28}$ by 28; for between-study comparisons, this measure was expressed per 40,000 IU (1 mg) vitamin D3 by dividing $\Delta \mathrm{Cavg}_{28}$ by the dose administered (1.75 mg). Cmax, $\Delta \mathrm{Cmax}_{\text {, Tmax, }} \mathrm{AUC}_{28 / 35}$, and $\mathrm{AUC}_{56 / 70}$ were summarized within groups by geometric means and 95\% CIs, and then log-transformed for oneway analyses of variance (ANOVA) to test for differences between the pregnant and non-pregnant groups. To plot the longitudinal change in [25(OH)D] over time using all available data $(\mathrm{N}=61)$, mean $[25(\mathrm{OH}) \mathrm{D}]$ at each visit were predicted from a linear regression model using a random intercept for each participant, with each visit represented by its own fixed indicator variable. Crosssectional differences in $\Delta[25(\mathrm{OH}) \mathrm{D}]$ between pregnant and non-pregnant groups at specific days of follow-up were compared by ANOVA. Changes in biochemical ([Ca] and $\mathrm{Ca}: \mathrm{Cr}$ ) and clinical outcomes from baseline were analyzed using generalized estimating equations (GEE) to account for repeated measures. The association between cord venous $[25(\mathrm{OH}) \mathrm{D}]$ and the corresponding maternal $[25(\mathrm{OH}) \mathrm{D}]$ closest in time to delivery was analyzed using Pearson correlation.

The target sample size of at least 12 analyzable participants per single-dose group was originally justified as follows: assuming two samples per subject (baseline and peak), a standard deviation for the $\Delta C$ max of $20 \mathrm{nmol} / \mathrm{L}$ and an intra-subject correlation of 0.6 , we anticipated that at least 12 women in each group would enable the estimation of the mean $\Delta C$ max with $95 \%$ confidence bounds of $\pm 10 \mathrm{nmol} / \mathrm{L}$. In all analyses, $P$ values less than 0.05 were considered to be statistically significant, with corrections for multiple comparisons using the Holm 
Table 1 Changes in [25(OH)D] following a single dose of 70,000 IU vitamin D3 in non-pregnant and pregnant women in Dhaka, Bangladesh ${ }^{\mathrm{a}}$

\begin{tabular}{|c|c|c|c|c|}
\hline & All participants & Non-pregnant & Pregnant & $P^{b}$ \\
\hline N (all participants) & 61 & 34 & 27 & \\
\hline \multicolumn{5}{|c|}{ Baseline $[25(\mathrm{OH}) \mathrm{D}](\mathrm{N}=61)$} \\
\hline Mean $[95 \% \mathrm{Cl}]$ & $47[42,52]$ & $54[47,62]$ & $39[34,45]$ & 0.01 \\
\hline Range & 21,96 & 27,96 & 21,95 & \\
\hline
\end{tabular}

$\Delta[25(\mathrm{OH}) \mathrm{D}]$, Mean $[95 \% \mathrm{Cl}], \mathrm{nmol} / \mathrm{L}$

Day $2(\mathrm{~N}=27)$
Day $4(\mathrm{~N}=27)$
Day $7(\mathrm{~N}=29)$
Day $21(\mathrm{~N}=14)$
Day $56(\mathrm{~N}=12)$

Participants in single-dose only groups

$\mathrm{N}$ (\% followed more than 7 days)

\# Specimens per participant

Median

Range

Baseline [25(OH)D] $(\mathrm{N}=31)$

Mean $[95 \% \mathrm{Cl}]$

Range

Tmax, days ( $\mathrm{N}=\mathbf{3 1})$

Mean $[95 \% \mathrm{Cl}]$

Range

Cmax, nmol/L ( $\mathrm{N}=31)$

Mean $[95 \% \mathrm{Cl}]$

Range

$\Delta \mathrm{Cmax}, \mathrm{nmol} / \mathrm{L}(\mathrm{N}=31)$

Mean $[95 \% \mathrm{Cl}]$

Range

Area under the curve, $\mathrm{nmol} \cdot \mathrm{d} / \mathrm{L}^{\mathrm{c}}$

$\mathrm{AUC}_{56 / 70}$, Mean ( $\left.\mathrm{N}=30\right)$

$[95 \% \mathrm{Cl}]$

$\mathrm{AUC}_{28 / 35}$, Mean ( $\left.\mathrm{N}=31\right)$

[95\% Cl]

$\Delta$ Cavg $_{28 / 35}$ per $\mathrm{mg}$ dose ${ }^{\mathrm{d}}(\mathrm{nmol} / \mathrm{L} / \mathrm{mg})$

$$
\begin{aligned}
& 20[15,25] \\
& 23[18,30] \\
& 26[21,33] \\
& 25[18,35] \\
& 16[11,23]
\end{aligned}
$$

$31(51 \%)$

6

3,6
$48[41,56]$
21,96

$11[7,18]$

2,70

$85[77,93]$

51,164
$30[23,39]$
2,87

$28[18,42]$

2,87

$87[75,101]$

51, 164

$52[42,64]$

27,96

$9[4,17]$

$17[10,29]$

2,70

$15[11,22]$

$23[16,32]$

$28[20,40]$

0.800

$25[18,34]$

$32[20,51]$

$20[12,33]$

13 (48\%)

3,6

$43[34,55]$

21,95

2,70

$82[72,92]$

52, 116

$33[24,46]$

9,52

969

$[563,1668]$

$[651,1343]$

591

$[448,780]$
910

[531, 1559]

562

$[383,823]$
632

0.672

[398, 1003]
0.134

0.003

0.224

0.134

0.500

0.486
[95\% Cl]

$12[10,15]$

$12[8,15]$

$14[10,18]$

a. $[25(\mathrm{OH}) \mathrm{D}]$ summary measures are geometric means with exponentiated $95 \%$ confidence intervals, unless otherwise indicated.

b. One-way analysis of variance (ANOVA) test for difference between non-pregnant and pregnant groups.

c. AUC was only estimated using data from participants with follow-up to the end of the interval of interest (i.e., 28/35 days or 56/70 days).

d. Average $[25(\mathrm{OH}) \mathrm{D}]$ over the first 28 or 35 days, per $\mathrm{mg}$ of the single vitamin D3 dose. Arithmetic means and $95 \%$ confidence intervals reported because these estimates had an approximately normal distribution. 
method, applied where appropriate [17]. Analyses were conducted using Stata version 10 and 11 (Stata Corporation, College Station, Texas).

\section{Results}

In the single-dose only groups, follow-up for the full 10 weeks was completed in all non-pregnant $(\mathrm{N}=18)$ and pregnant $(\mathrm{N}=13)$ participants; however, the terminal serum sample for one non-pregnant participant (at day 56) was not suitable for analysis. Cord blood specimens were available for 12 of 13 pregnant participants in the single-dose only group. An additional 16 non-pregnant and 14 pregnant participants enrolled in weekly-dose groups contributed at least one $[25(\mathrm{OH}) \mathrm{D}]$ value on or prior to day 7 .

At baseline, pregnant participants had lower average $[25(\mathrm{OH}) \mathrm{D}]$ than non-pregnant participants (Table 1); this was partly attributable to the design of the study, whereby some pregnant women were enrolled in the winter and all non-pregnant women were enrolled in the summer and fall (Table 2). Pregnant participants were generally younger, more likely to be married, and of a slightly lower socioeconomic status than non-pregnant participants (Table 2).

\section{Pharmacokinetic outcomes}

There was substantial inter-individual variation in the shape and magnitude of $25(\mathrm{OH}) \mathrm{D}$ responses to a single oral dose of 70,000 IU vitamin D3. However, the population-average pattern consisted of an abrupt increase in $[25(\mathrm{OH}) \mathrm{D}]$ in the first week, followed by a peak within the first three weeks, and then a gradual return to baseline over the ensuing two months in both non-pregnant and pregnant participants (Figure 3$)$. The average $[25(\mathrm{OH}) \mathrm{D}]$ remained marginally above baseline at ten weeks after supplementation. There were minor differences between the pregnant and nonpregnant groups in the average $\Delta[25(\mathrm{OH}) \mathrm{D}]$ throughout follow-up (Table 1). In particular, $[25(\mathrm{OH}) \mathrm{D}]$ rose more rapidly and the peak average occurred earlier in the nonpregnant group. This was demonstrated by the significantly greater $\Delta[25(\mathrm{OH}) \mathrm{D}]$ on day 2 , the significantly lower $\Delta[25(\mathrm{OH}) \mathrm{D}]$ on day 21 , and the slightly earlier occurrence of Tmax in non-pregnant vs. pregnant women (Table 1). Moreover, there was greater variance in the early $\Delta[25(\mathrm{OH})$ D] in non-pregnant vs. pregnant participants (Figure 3). The highest $[25(\mathrm{OH}) \mathrm{D}]$ in any non-pregnant participant was $164 \mathrm{nmol} / \mathrm{L}$, whereas the maximum in any pregnant participant was $116 \mathrm{nmol} / \mathrm{L}$. On average, pregnant women

Table 2 Personal and household characteristics of participants at enrollment

\begin{tabular}{|c|c|c|c|c|c|c|}
\hline & \multicolumn{3}{|c|}{ Single-dose only group } & \multicolumn{3}{|c|}{ All participants } \\
\hline & Non-pregnant & Pregnant & $P$ & Non-pregnant & Pregnant & $P^{a}$ \\
\hline \# Enrolled & 18 & 13 & & 34 & 27 & \\
\hline \multicolumn{7}{|l|}{ Month of enrollment } \\
\hline July-August, 2009 & $18(100 \%)$ & $5(38 \%)$ & $<0.001$ & $33(97 \%)$ & $5(19 \%)$ & $<0.001$ \\
\hline Sept-Oct 2009 & 0 & $8(62 \%)$ & & $1(3 \%)$ & $8(30 \%)$ & \\
\hline February 2010 & 0 & 0 & & 0 & $14(52 \%)$ & \\
\hline Age (years), Mean $( \pm S D)$ & $23.9( \pm 3.8)$ & $20.9( \pm 2.7)$ & 0.022 & $24.2( \pm 4.1)$ & $21.6( \pm 2.9)$ & 0.006 \\
\hline Married & $11(61 \%)$ & $13(100 \%)$ & 0.025 & $23(68 \%)$ & $27(100 \%)$ & 0.001 \\
\hline \multicolumn{7}{|l|}{ Education level attained } \\
\hline None & $1(6 \%)$ & $2(15 \%)$ & 0.750 & $3(9 \%)$ & $6(22 \%)$ & 0.293 \\
\hline Primary & $11(61 \%)$ & $7(54 \%)$ & & $21(62 \%)$ & $16(59 \%)$ & \\
\hline Secondary or higher & $6(33 \%)$ & $4(31 \%)$ & & $10(29 \%)$ & $5(19 \%)$ & \\
\hline \multicolumn{7}{|l|}{ Husband's education level } \\
\hline None & $2(18 \%)$ & $3(23 \%)$ & 1.000 & $2(9 \%)$ & $4(15 \%)$ & 0.786 \\
\hline Primary & $4(36 \%)$ & $4(31 \%)$ & & $10(43 \%)$ & $13(48 \%)$ & \\
\hline Secondary or higher & $5(45 \%)$ & $6(46 \%)$ & & $11(48 \%)$ & $10(37 \%)$ & \\
\hline Home ownership & $6(33 \%)$ & $1(8 \%)$ & 0.191 & $7(21 \%)$ & $2(7 \%)$ & 0.276 \\
\hline \multicolumn{7}{|c|}{ House constructed from cement, brick or tile ${ }^{b}$} \\
\hline Floor & $18(100 \%)$ & $11(85 \%)$ & 0.168 & $33(98 \%)$ & $22(81 \%)$ & 0.079 \\
\hline Walls & $16(89 \%)$ & $10(77 \%)$ & 0.625 & $30(88 \%)$ & $18(67 \%)$ & 0.042 \\
\hline Roof & $6(33 \%)$ & $6(46 \%)$ & 0.710 & $13(38 \%)$ & $7(26 \%)$ & 0.412 \\
\hline Height $(\mathbf{c m})$, mean $( \pm S D)$ & $149.7( \pm 3.7)$ & $150.3( \pm 3.9)$ & 0.685 & $150.8( \pm 4.3)$ & $150.5( \pm 4.3)$ & 0.758 \\
\hline
\end{tabular}

a. ANOVA for comparisons of continuous variables, Fisher's exact test for categorical variables.

b. In comparison to tin or natural materials (e.g., earth, bamboo). 

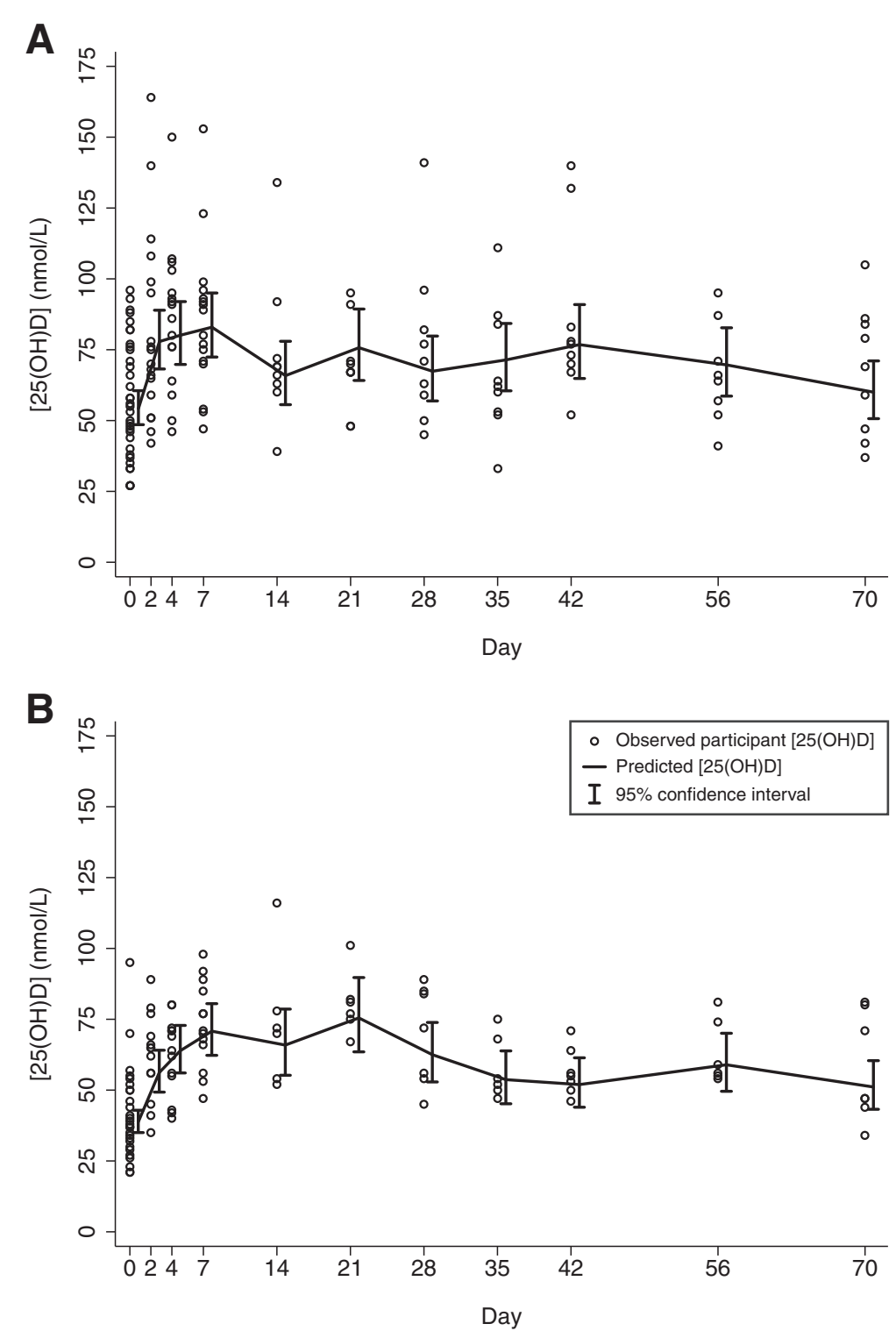

Figure 3 Serum [25(OH)D] in non-pregnant (A) and pregnant (B) participants following administration of 70,000 IU vitamin D3 at day 0. Predicted mean $[25(\mathrm{OH}) \mathrm{D}]$ and $95 \%$ confidence intervals were estimated in a random-intercept regression model of $\ln [25(\mathrm{OH}) \mathrm{D}]$ as a function of time.

had slightly lower absolute Cmax, but the mean maximal rise in $[25(\mathrm{OH}) \mathrm{D}]$ (i.e., $\Delta \mathrm{Cmax}$ ) and AUC were similar in pregnant and non-pregnant women (Table 1). Overall, the [25(OH)D] was an average of $19 \mathrm{nmol} / \mathrm{L}$ (95\% CI, 14 to 25) higher than baseline during the first month after supplementation, which corresponded to a gain of approximately $12 \mathrm{nmol} / \mathrm{L}$ per mg of the vitamin D3 dose (Table 1).

\section{Safety outcomes}

The supplement was tasteless and well tolerated and there were no supplement-related adverse events (Table 3). The stillbirth and newborn deaths were explained by medical problems, and there was no evidence that either was related to the vitamin $\mathrm{D}$ supplementation, given their timing (i.e., did not occur at peak $[25(\mathrm{OH}) \mathrm{D}])$ and the absence of biochemical evidence of vitamin D toxicity in the mother (Table 3). Postmortem examinations were not feasible in the study setting. Two other AEs resolved without complications and occurred in the absence of evidence of vitamin D toxicity (Table 3). Pregnancy and birth outcome metrics were consistent with expectations for the source population (Table 4).

Changes in average serum calcium concentrations (Figure 4) and urinary calcium excretion (Figure 5) occurred during the early phase of $[25(\mathrm{OH}) \mathrm{D}]$ escalation. In non-pregnant participants, a transient increase in 
Table 3 Individual cases of elevated serum calcium or clinical adverse events among pregnant participants who received $70,000 \mathrm{IU}$ vitamin $\mathrm{D} 3^{\mathrm{a}}$

\begin{tabular}{|c|c|c|c|c|c|c|c|c|}
\hline \multirow[b]{2}{*}{ ID } & \multirow{2}{*}{$\begin{array}{r}\text { Event } \\
\text { Description }\end{array}$} & \multicolumn{5}{|c|}{ Biochemistry ${ }^{b}$} & \multirow[t]{2}{*}{ Action } & \multirow[t]{2}{*}{ Outcome } \\
\hline & & Time of onset & Timing & $\begin{array}{l}\text { Albumin -adjusted } \\
\text { serum }[\mathrm{Ca}] \\
\text { (mmol/L) }\end{array}$ & $\begin{array}{l}\text { Urine } \mathrm{Ca}: \mathrm{Cr} \\
(\mathrm{mmol} / \mathrm{mmol})\end{array}$ & $\begin{array}{l}{[25(\mathrm{OH}) \mathrm{D}]} \\
(\mathrm{nmol} / \mathrm{L})\end{array}$ & & \\
\hline \multirow[t]{5}{*}{1} & \multirow{5}{*}{$\begin{array}{l}\text { Neonatal: } \\
\text { Neonatal death, } \\
\text { secondary to } \\
\text { respiratory failure, } \\
\text { and pulmonary } \\
\text { hemorrhage. }\end{array}$} & \multirow{5}{*}{$\begin{array}{l}\text { Delivery at } 36 \\
\text { weeks gestation; } \\
\text { day } 42 \text { of follow-up. }\end{array}$} & Baseline & 2.43 & 0.05 & 95 & \multirow{5}{*}{$\begin{array}{l}\text { Admitted to } \\
\text { a neonatal } \\
\text { intensive } \\
\text { care unit. }\end{array}$} & \multirow{5}{*}{$\begin{array}{l}\text { Newborn died } \\
\text { in hospital on } \\
\text { postnatal day } \\
\text { 3. No maternal } \\
\text { complications. }\end{array}$} \\
\hline & & & Event & 2.38 & 0.74 & 71 & & \\
\hline & & & Post-event & 2.46 & 0.16 & 80 & & \\
\hline & & & Range & 2.38 to 2.48 & 0.05 to 0.74 & 71 to 116 & & \\
\hline & & & Cord blood & 2.69 & - & 72 & & \\
\hline \multirow[t]{5}{*}{2} & \multirow{5}{*}{$\begin{array}{l}\text { Pregnancy: } \\
\text { Referral to } \\
\text { hospital due to } \\
\text { severe headache } \\
\text { and vomiting. }\end{array}$} & \multirow{5}{*}{$\begin{array}{l}32 \text { weeks gestation; } \\
\text { day } 17 \text { of follow-up. }\end{array}$} & Baseline & 2.25 & 0.22 & 46 & \multirow{5}{*}{$\begin{array}{l}\text { Admitted to } \\
\text { tertiary-care } \\
\text { hospital. }\end{array}$} & \multirow{5}{*}{$\begin{array}{l}\text { Discharged on } \\
\text { day } 2 \text { of } \\
\text { admission; no } \\
\text { further } \\
\text { complications. } \\
\text { Delivered term } \\
\text { infant; no } \\
\text { complications. }\end{array}$} \\
\hline & & & Event & 2.26 & 0.74 & 85 & & \\
\hline & & & Post-event & 2.29 & 1.04 & 75 & & \\
\hline & & & Range & 2.24 to 2.37 & 0.22 to 1.04 & 46 to 85 & & \\
\hline & & & Cord blood & 2.51 & - & 49 & & \\
\hline \multirow[t]{7}{*}{3} & \multirow{3}{*}{$\begin{array}{l}\text { Pregnancy: } \\
\text { Physician } \\
\text { suspected } \\
\text { irregular fetal } \\
\text { heart rate; } \\
\text { asymptomatic. }\end{array}$} & \multirow{3}{*}{$\begin{array}{l}34 \text { weeks gestation; } \\
\text { day } 28 \text { of follow-up. }\end{array}$} & Baseline & 2.30 & 0.39 & 54 & \multirow{3}{*}{$\begin{array}{l}\text { Assessment } \\
\text { at tertiary- } \\
\text { care hospital. }\end{array}$} & \multirow{3}{*}{$\begin{array}{l}\text { Normal } \\
\text { biophysical } \\
\text { profile; normal } \\
\text { pregnancy. No } \\
\text { intervention } \\
\text { required. }\end{array}$} \\
\hline & & & Event & 2.45 & 0.18 & 54 & & \\
\hline & & & Post-event & 2.50 & $\begin{array}{l}\text { 1.48; repeat } \\
\text { was } 0.66\end{array}$ & 53 & & \\
\hline & \multirow{4}{*}{$\begin{array}{l}\text { Pregnancy: } \\
\text { Isolated albumin- } \\
\text { adjusted serum } \\
\text { [Ca] of } 2.61 \\
\mathrm{mmol} / \mathrm{L} .\end{array}$} & \multirow{4}{*}{$\begin{array}{l}1 \text { week post- } \\
\text { partum; day } 70 \text { of } \\
\text { follow-up }\end{array}$} & Event & 2.61 & 0.6 & 47 & \multirow{4}{*}{$\begin{array}{l}\text { Repeat } \\
\text { biochemistry } \\
\text { was normal. } \\
\text { No } \\
\text { intervention } \\
\text { required }\end{array}$} & \multirow{4}{*}{$\begin{array}{l}\text { Asymptomatic. } \\
\text { No maternal or } \\
\text { newborn } \\
\text { complications } \\
\text { (delivery } \\
\text { occurred at } 39 \\
\text { weeks } \\
\text { gestation). }\end{array}$} \\
\hline & & & Post-event & 2.52 & - & 30 & & \\
\hline & & & Range & 2.3 to 2.61 & 0.14 to 1.74 & 47 to 70 & & \\
\hline & & & Cord blood & 2.61 & - & 30 & & \\
\hline \multirow[t]{5}{*}{4} & \multirow{5}{*}{$\begin{array}{l}\text { Pregnancy: } \\
\text { Intrauterine fetal } \\
\text { death, associated } \\
\text { with placental } \\
\text { abruption, } \\
\text { hypertension and } \\
\text { possible } \\
\text { abdominal } \\
\text { trauma. }\end{array}$} & \multirow{5}{*}{$\begin{array}{l}35 \text { weeks, } 5 \text { days } \\
\text { gestational age. }\end{array}$} & Baseline & 2.38 & 0.02 & 21 & \multirow{5}{*}{$\begin{array}{l}\text { Fetus } \\
\text { delivered by } \\
\text { cesarean } \\
\text { section. }\end{array}$} & \multirow{5}{*}{$\begin{array}{l}\text { Intrauterine } \\
\text { fetal death, } \\
\text { secondary to } \\
\text { placental } \\
\text { abruption. No } \\
\text { further } \\
\text { maternal } \\
\text { complications }\end{array}$} \\
\hline & & & Event & 2.38 & 0.05 & 45 & & \\
\hline & & & Post-event & 2.46 & 0.05 & 46 & & \\
\hline & & & Range & 2.31 to 2.46 & 0.02 to 0.57 & 21 to 52 & & \\
\hline & & & Cord blood & 2.28 & - & 29 & & \\
\hline
\end{tabular}

\footnotetext{
a. Table includes participants with at least one serum albumin-adjusted calcium concentration measurement greater than $2.60 \mathrm{mmol} / \mathrm{L}$ or a serious clinical adverse event at any time during follow-up, among participants in the single-dose only group.

b. All values refer to serum concentrations in maternal venous blood except for the row labeled "cord blood". "Range" refers to the participant's range of values during the entire follow-up period.
}

albumin-adjusted serum [Ca] from baseline was notable on day 4 (Table 5; Figure 4). The corresponding change in unadjusted total serum [Ca] was smaller and non-significant, and the raised adjusted [Ca] coincided with a lower average serum albumin on day 4 (difference versus baseline, $-1.23 \mathrm{~g} / \mathrm{L} ; 95 \% \mathrm{CI},-2.12$ to -0.34$)$. In pregnant participants, there was an initial increase in albumin-adjusted [Ca] beginning on day 2 that persisted until nearly the end of the observation period (Figure 4), but the difference from baseline was only statistically significant on day 7 (Table 6). The unadjusted total $[\mathrm{Ca}]$ did not vary greatly from baseline and serum albumin remained relatively stable until the end of the 70-day follow-up, when many of the participants were post-partum.

There were no episodes of confirmed hypercalcemia according to the study definition, and no isolated albuminadjusted $[\mathrm{Ca}$ ] values greater than the recent IOM upper limit of normal of $2.63 \mathrm{mmol} / \mathrm{L}$. One pregnant participant had a single albumin-adjusted $[\mathrm{Ca}]=2.61 \mathrm{mmol} / \mathrm{L}$ at oneweek postpartum (70 days after dose administration) corresponding to a normal total [Ca] $(2.51 \mathrm{mmol} / \mathrm{L}$; serum albumin concentration was $35.8 \mathrm{~g} / \mathrm{L}$ ) that was within the reference range on repeat testing 4 days later (Table 3; Figure 6). A further follow-up one week following the first 
Table 4 Pregnancy and newborn outcomes for pregnant participants who received only a single dose of 70,000 IU vitamin $D$ at enrollment and were followed up to delivery

\begin{tabular}{|c|c|}
\hline $\mathbf{N}$ & 13 \\
\hline Gestational age at birth, weeks (by LMP) ${ }^{a}$ Mean $( \pm S D)$ & $38.8( \pm 1.8)$ \\
\hline Range & $35.7-42.0$ \\
\hline Preterm, n (\%) & $2(15 \%)$ \\
\hline \multicolumn{2}{|l|}{ Birth weight $^{\mathbf{b}}(\mathrm{g})$} \\
\hline Mean $( \pm S D)^{c}$ & $2441( \pm 354)$ \\
\hline Range (g) & $1890-3005$ \\
\hline n/N (\%) Low Birth Weight & $6 / 12(50 \%)$ \\
\hline Delivery mode, $\mathrm{n} / \mathrm{N}(\%)$ Cesarean section ${ }^{d}$ & $8 / 13(62 \%)$ \\
\hline Sex, n (\%) female & $5(38 \%)$ \\
\hline Live births ${ }^{\text {e }}$ & $12 / 13$ \\
\hline Alive at 1 month of age ${ }^{f}$ & $11 / 13$ \\
\hline
\end{tabular}

a. In a sample of 113 deliveries at the study site (October 2009 to January 2010) for which there was a recalled first day of last menstrual period, the mean gestational age at birth was estimated to be 39.7 weeks $( \pm 2.2)$.

b. Only includes the 12 liveborn infants.

c. In a consecutive sample of 362 liveborn infants delivered at the study site (October 2009 to January 2010), the mean birth weight was $2780 \mathrm{~g}( \pm 440)$.

d. In a consecutive sample of 369 deliveries at the study site (October 2009 to January 2010), there were 199 cesarean deliveries (54\%).

e. There was one stillbirth. In a consecutive sample of 369 deliveries at the study site (October 2009 to January 2010), there were 7 stillbirths (2\%).

f. There was one neonatal death at 3 days of age.

abnormal result was also normal (albumin-adjusted serum [Ca] of $2.44 \mathrm{mmol} / \mathrm{L}$ ). This participant also had two nonconsecutive episodes of urinary ca:cr higher than 1.0 $\mathrm{mmol} / \mathrm{mmol}$ during follow-up (Figure 6). Her serum biochemical patterns were consistent with the expected changes in the perinatal period, including a gradual increase in albumin-adjusted serum [Ca] towards the end of the antenatal period and a rapid increase in serum albumin in the post-partum period [18]. Furthermore, there was no temporal association between the rise in $[25(\mathrm{OH}) \mathrm{D}]$ and either the occurrence of isolated peaks in urine ca:cr or the isolated elevated [Ca] (Figure 6).

None of the participants manifested persistent hypercalciuria according to the study definition, or using a more conservative threshold of $0.85 \mathrm{mmol} / \mathrm{mmol}$. In nonpregnant participants, the $\mathrm{Ca}: \mathrm{Cr}$ increased from baseline but differences were only statistically significant at day 7 and 14 (Table 5). In pregnant participants, the increases in average $\mathrm{Ca}: \mathrm{Cr}$ above baseline were more persistent and were statistically significant on all days except day 42,49 , and 70 (Table 6). There was no overall difference in the average ca:cr between non-pregnant and pregnant participants $(P=0.857)$.

\section{Cord blood biochemistry}

Among participants who had received a single dose at baseline and for whom cord blood specimens were collected
$(\mathrm{N}=12)$, the geometric mean cord serum $[25(\mathrm{OH}) \mathrm{D}]$ was 50 $\mathrm{nmol} / \mathrm{L}$ (95\% CI, 40 to 62; range, 29 to 80 ). All cord serum albumin-adjusted $[\mathrm{Ca}]$ were within the normal range. The cord $\ln [25(\mathrm{OH}) \mathrm{D}]$ was moderately correlated with the maternal $\ln [25(\mathrm{OH}) \mathrm{D}]$ closest to the time of delivery (Pearson rho $=0.64, P=0.02$ ), and the average ratio of cord:maternal [25(OH)D] $(\mathrm{N}=12)$ was $0.88(95 \% \mathrm{CI}, 0.76-1.02)$.

\section{Discussion}

This single-dose oral vitamin D3 pharmacokinetic study generated novel observations regarding the biochemical response to vitamin D3 in women of reproductive age in South Asia. Overall, we found that the average response was similar to that reported for non-pregnant adults in other geographic settings. The occurrence of the maximal mean $[25(\mathrm{OH}) \mathrm{D}]$ in the first month was consistent with previous studies of single-dose vitamin D3 (1.25 to $15 \mathrm{mg}$ ) administered to non-pregnant adults in North America, Europe and Australia [10,11,19-23]. When expressed as a function of vitamin D3 dose (assuming the rise is linearly proportional to dose), the mean overall $\Delta$ Cmax of 30 $\mathrm{nmol} / \mathrm{L}(28 \mathrm{nmol} / \mathrm{L}$ in non-pregnant and $33 \mathrm{nmol} / \mathrm{L}$ in pregnant participants) represented an average maximal rise in $[25(\mathrm{OH}) \mathrm{D}]$ of $\sim 17 \mathrm{nmol} / \mathrm{L}$ per $\mathrm{mg} \mathrm{D} 3$. This estimate was similar to those of previous studies from which relevant inferences could be drawn, in which the average $\Delta$ Cmax ranged from 12 to $16 \mathrm{nmol} / \mathrm{L}$ per $\mathrm{mg}$ of vitamin D3 $[10,11,19,20]$.

We are not aware of previous single-dose vitamin D3 pharmacokinetic studies in pregnancy to which the present findings can be directly compared. However, there are emerging data regarding the efficacy and safety of highdose continuous regimens in pregnancy; for example, Hollis et al. reported that $4000 \mathrm{IU} /$ day vitamin D3 initiated in the 2nd trimester yielded an increase in mean $[25(\mathrm{OH}) \mathrm{D}]$ from $58 \mathrm{nmol} / \mathrm{L}$ to $111 \mathrm{nmol} / \mathrm{L}$ at delivery among women in South Carolina, without inducing hypercalcemia or other observed adverse effects [24]. In comparison, Vieth observed in non-pregnant adults that $4000 \mathrm{IU} /$ day led to an increase in mean $[25(\mathrm{OH}) \mathrm{D}]$ from 38 to $96 \mathrm{nmol} / \mathrm{L}$ at steady-state [16]. Thus, from a pharmacokinetic standpoint, the Hollis et al. findings are in accord with our conclusion that pregnancy does not substantially alter the $25(\mathrm{OH}) \mathrm{D}$ response to vitamin D3.

There was substantial inter-individual variability in 25 $(\mathrm{OH}) \mathrm{D}$ responses. Many participants demonstrated a rapid rise in $[25(\mathrm{OH}) \mathrm{D}]$ during the first week, which is similar to the response to an acute dose of ultraviolet radiation exposure [25]; but distinct from the more gradual effects of other forms of exogenous vitamin D intake (e.g., oral D2 ingestion [10]). Several non-pregnant participants demonstrated peak $[25(\mathrm{OH}) \mathrm{D}]$ as early as two days after supplement delivery, and there was notably wider variability in responses in the group of non-pregnant participants 

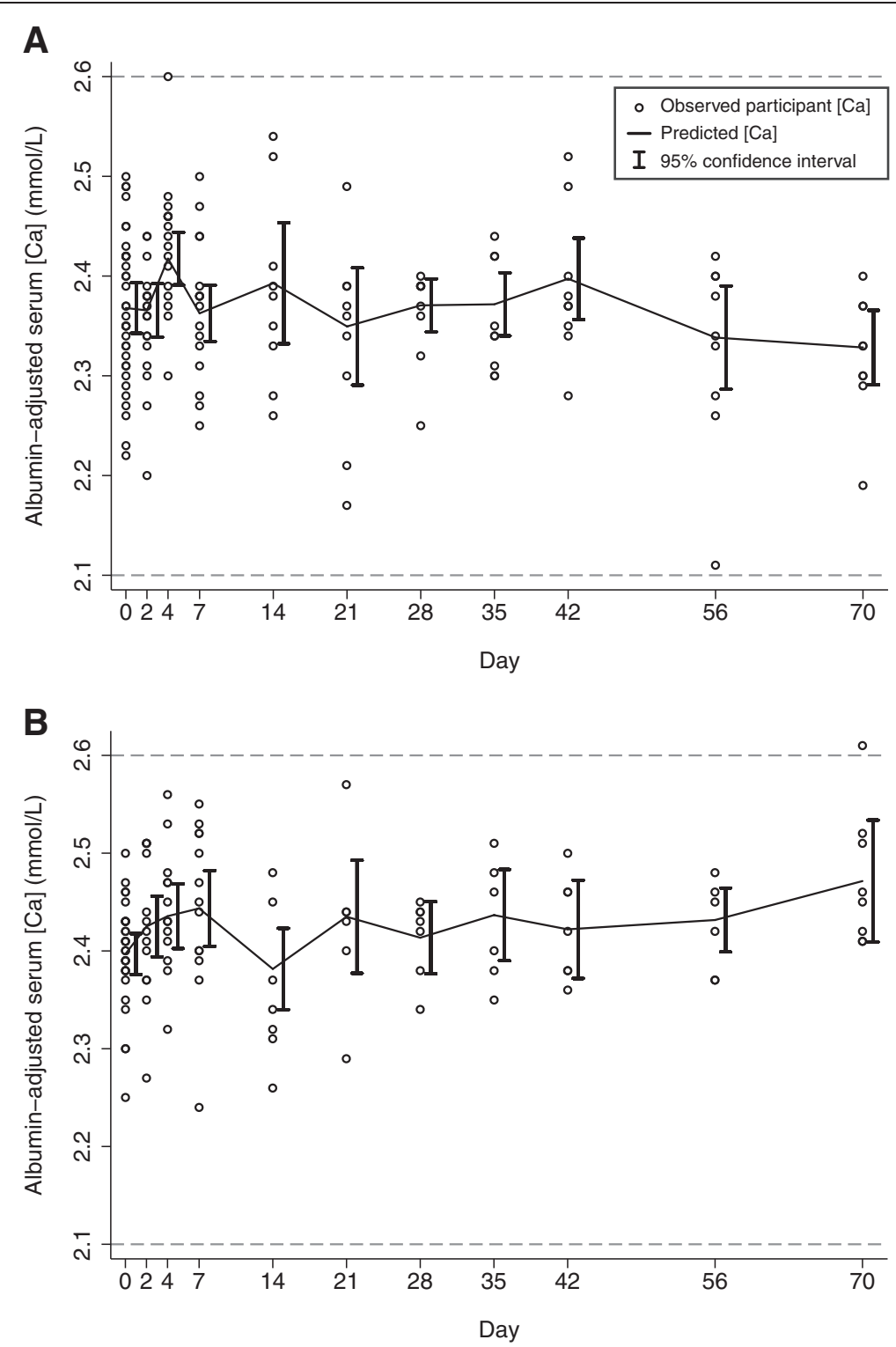

Figure 4 Albumin-adjusted serum calcium concentration ([Ca]) in non-pregnant (A) and pregnant participants (B) following administration of vitamin D3 70,000 IU at day $\mathbf{0}$. Dashed horizontal lines represent upper and lower bounds of the reference range. Predicted means and 95\% confidence intervals were estimated in a linear regression model using GEE.

during the early escalation phase compared to pregnant participants. It is possible that the greater apparent variability was an artifact due to lower precision of the 25 $(\mathrm{OH}) \mathrm{D}$ assay at higher $[25(\mathrm{OH}) \mathrm{D}]$, given the higher average $[25(\mathrm{OH}) \mathrm{D}]$ in non-pregnant women. Higher concentrations of vitamin D-binding protein during pregnancy [[26] may have efficiently buffered the absorbed vitamin D3 and slowed its transport to the liver where it undergoes 25-hydroxylation [27]].

Vitamin D3 bioavailability (measured by mean AUC and dose-adjusted $\Delta$ Cavg $\left._{28}\right)$ differed minimally between the non-pregnant and pregnant groups, and between-group differences were overshadowed by between-subject variability. The overall $\Delta \mathrm{Cavg}_{28}$ (i.e., estimated average [25 $(\mathrm{OH}) \mathrm{D}]$ rise from baseline in the first month, expressed per milligram of vitamin D3) was $12 \mathrm{nmol} / \mathrm{L} / \mathrm{mg}$ based on an aggregate analysis of individual empiric AUCs. This result was the same as the $\Delta \operatorname{Cavg}_{28}$ of $\sim 12 \mathrm{nmol} / \mathrm{L} / \mathrm{mg}$ found in studies of non-pregnant adults using 50,000 IU and 100,000 IU [11]], and similar to an extrapolated estimate of $13 \mathrm{nmol} / \mathrm{L} / \mathrm{mg}$ based on data reported for a single dose of 300,000 IU in elderly adults [19]. The $\Delta \mathrm{Cavg}_{28}$ provides a useful summary measure for between-study comparisons because most of a single ingested vitamin D3 dose is converted to $25(\mathrm{OH}) \mathrm{D}$ within one month [11]. The consistency of the present findings with $\Delta \mathrm{Cavg}_{28}$ estimates from 

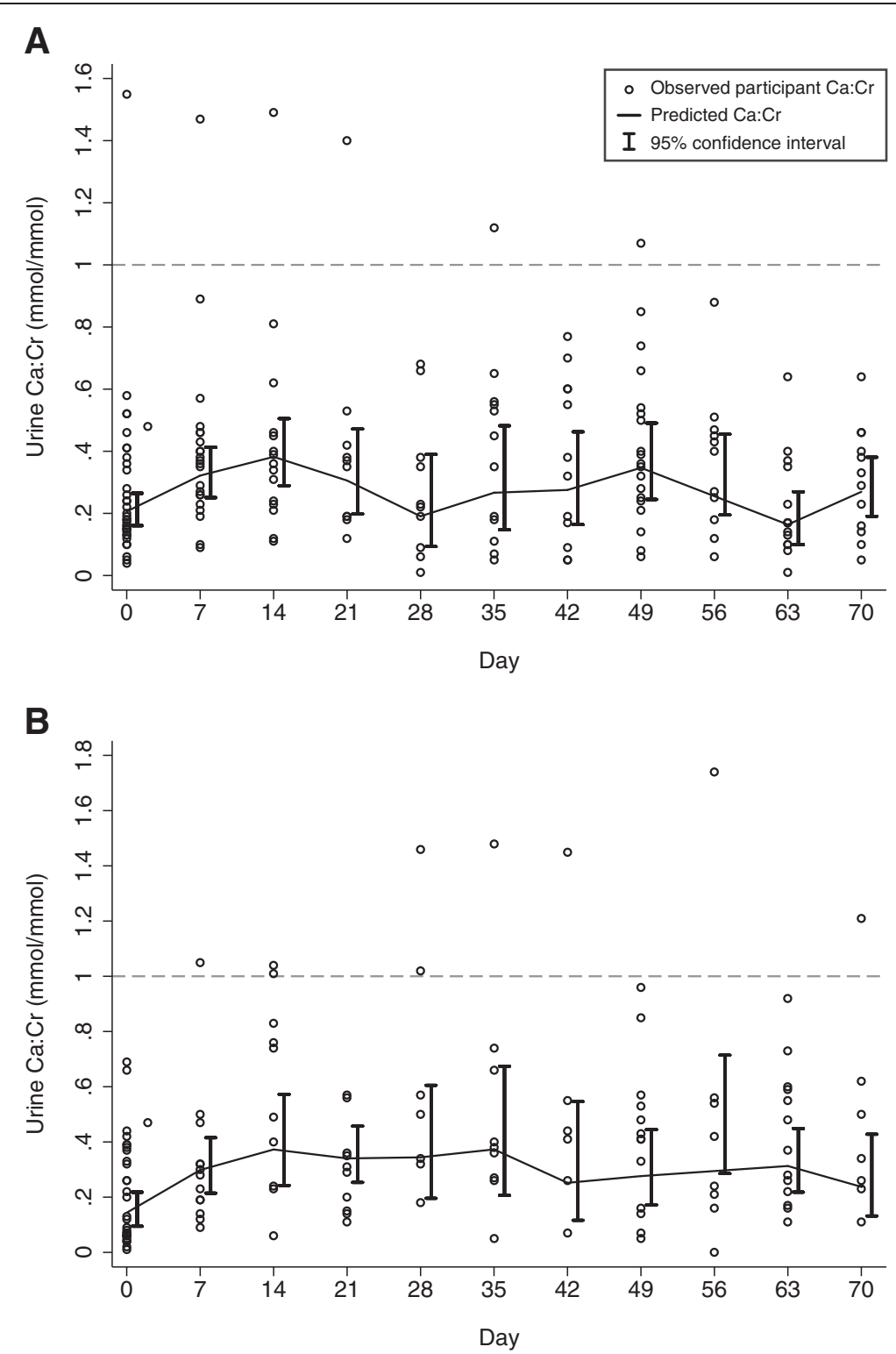

Figure 5 Calcium:creatinine ratios $(\mathrm{Ca}: \mathrm{Cr}$ ) in spot urine specimens from non-pregnant $(\mathrm{A})$ and pregnant participants (B) following administration of vitamin D3 70,000 IU at day 0. Predicted means and 95\% confidence intervals were estimated in a linear regression model using GEE, in which log-transformed Ca:Cr was modeled as a function of time.

previous studies supports the contention by Heaney et al. that $25(\mathrm{OH}) \mathrm{D}$ bioavailability is proportional to vitamin $\mathrm{D} 3$ input across a wide dose range (1.25 to $7.5 \mathrm{mg})$ [11]. Notably, $\Delta$ Cavg $_{28}$ extracted from a study by Cipriani et al. was somewhat lower $(\sim 8 \mathrm{nmol} / \mathrm{L} / \mathrm{mg})[20]$. We speculate that the massive dose administered in that study (600,000 IU) saturated the hepatic 25-hydroxylase system, resulting in the engagement of subsidiary vitamin D catabolic pathways which reduced the $25(\mathrm{OH}) \mathrm{D}$ yield.

The single vitamin D3 dose of 70,000 IU did not provoke hypercalcemia or hypercalciuria in non-pregnant or pregnant participants, and available data indicated that adverse perinatal events were neither temporally nor mechanistically linked to vitamin D supplementation. An isolated serum $[\mathrm{Ca}$ ] value above the reference range in one pregnant participant occurred in the early postpartum period, when albumin-adjusted [Ca] typically peaks [18]. This was not due to vitamin $\mathrm{D}$ toxicity because her $[25(\mathrm{OH}) \mathrm{D}]$ at the time was $47 \mathrm{nmol} / \mathrm{L}$ and the $[\mathrm{Ca}]$ rapidly and spontaneously normalized. However, it is important to acknowledge that there were significant increases in average [Ca] and urine ca:cr. Changes in serum [Ca] were not reportedly significant in studies by Ilahi [11], Armas [10], or Romagnoli [19], but Cipriani et al. 
Table 5 Serum calcium and urinary calcium:creatinine following single-dose vitamin D3 (70,000 IU) in non-pregnant participants

\begin{tabular}{|c|c|c|c|c|c|c|c|c|c|c|}
\hline \multirow[b]{2}{*}{ Follow-up time } & \multirow[b]{2}{*}{$\mathrm{N}^{\mathrm{a}}$} & \multirow{2}{*}{$\begin{array}{l}\text { Total serum calcium conc. } \\
\text { (mmol/L) } \\
\text { Mean (SD) }\end{array}$} & \multicolumn{3}{|c|}{$\begin{array}{l}\text { Albumin-adjusted serum } \\
\text { calcium concentration } \\
\text { (mmol/L) }\end{array}$} & \multicolumn{5}{|c|}{$\begin{array}{l}\text { Urine calcium:creatinine ratio } \\
(\mathrm{mmol} / \mathrm{mmol})\end{array}$} \\
\hline & & & $\begin{array}{l}\text { Mean } \\
\text { (SD) }\end{array}$ & Range & $\begin{array}{l}\#> \\
2.60\end{array}$ & $\overline{\mathbf{N}^{\mathrm{a}}}$ & $\underset{b}{M e a n}$ & $\begin{array}{l}\text { Median } \\
\text { (IQR) }\end{array}$ & Range & $\begin{array}{l}\#> \\
1.0\end{array}$ \\
\hline 0 days & 34 & $2.45(0.08)$ & $\begin{array}{l}2.37 \\
(0.08)\end{array}$ & $\begin{array}{l}2.22 \text { to } \\
2.5\end{array}$ & 0 & 34 & 0.21 & $0.19(0.22)$ & $\begin{array}{l}0.04 \text { to } \\
1.55\end{array}$ & 1 \\
\hline 2 days & 18 & $2.44(0.07)$ & $\begin{array}{l}2.36 \\
(0.06)\end{array}$ & $\begin{array}{l}2.2 \text { to } \\
2.44\end{array}$ & 0 & - & - & - & - & - \\
\hline 4 days & 16 & $2.48(0.06)$ & $\begin{array}{l}2.42 \\
(0.07)^{c}\end{array}$ & 2.3 to 2.6 & 0 & - & - & - & - & - \\
\hline $\begin{array}{l}\text { 2nd to 4th week (days } 7 \text { to } \\
\text { 27) }\end{array}$ & 34 & $2.44(0.09)$ & $\begin{array}{l}2.37 \\
(0.08)\end{array}$ & $\begin{array}{l}2.17 \text { to } \\
2.54\end{array}$ & 0 & 47 & $0.34^{d}$ & $0.36(0.23)$ & $\begin{array}{l}0.09 \text { to } \\
1.49\end{array}$ & 3 \\
\hline $\begin{array}{l}\text { 5th to 8th week (days } 28 \text { to } \\
\text { 55) }\end{array}$ & 27 & $2.44(0.08)$ & $\begin{array}{l}2.38 \\
(0.06)\end{array}$ & $\begin{array}{l}2.25 \text { to } \\
2.52\end{array}$ & 0 & 53 & 0.28 & $0.35(0.37)$ & $\begin{array}{l}0.01 \text { to } \\
1.12\end{array}$ & 2 \\
\hline $\begin{array}{l}\text { 9th to } 11 \text { th week (days } 56 \text { to } \\
\text { 76) }\end{array}$ & 18 & $2.38(0.09)^{\mathrm{e}}$ & $\begin{array}{l}2.33 \\
(0.08)\end{array}$ & $\begin{array}{l}2.11 \text { to } \\
2.42\end{array}$ & 0 & 37 & 0.24 & $0.25(0.26)$ & $\begin{array}{l}0.01 \text { to } \\
0.88\end{array}$ & 0 \\
\hline Total & 147 & $2.44(0.09)$ & $\begin{array}{l}2.37 \\
(0.08)\end{array}$ & $\begin{array}{l}2.11 \text { to } \\
2.6\end{array}$ & 0 & 172 & 0.26 & $0.3(0.3)$ & $\begin{array}{l}0.01 \text { to } \\
1.55\end{array}$ & 6 \\
\hline
\end{tabular}

a. Number of specimens (there may have been multiple specimens for a single participant during a given follow-up period).

b. Geometric means.

c. Mean at day 4 was higher than baseline $(+0.05 ; 95 \% \mathrm{Cl}, 0.03$ to 0.07$)$ and this remained statistically significant after correction for multiples testing

d. Means at days 7 and 14 were significantly higher than baseline, after correction for multiple testing.

e. Mean at day 70 was significantly lower than baseline, after correction for multiple testing.

Table 6 Serum calcium and urinary calcium:creatinine following single-dose vitamin D3 (70,000 IU) in pregnant participants

\begin{tabular}{|c|c|c|c|c|c|c|c|c|c|c|}
\hline \multirow[b]{2}{*}{ Follow-up time } & \multirow[b]{2}{*}{$\mathrm{N}^{\mathrm{a}}$} & \multirow{2}{*}{$\begin{array}{l}\text { Total serum calcium conc. } \\
\text { (mmol/L) } \\
\text { Mean (SD) }\end{array}$} & \multicolumn{3}{|c|}{$\begin{array}{l}\text { Albumin-adjusted serum } \\
\text { calcium concentration } \\
\text { (mmol/L) }\end{array}$} & \multicolumn{5}{|c|}{$\begin{array}{l}\text { Urine calcium:creatinine ratio } \\
(\mathrm{mmol} / \mathrm{mmol})\end{array}$} \\
\hline & & & $\begin{array}{l}\text { Mean } \\
\text { (SD) }\end{array}$ & Range & $\begin{array}{l}\#> \\
2.60\end{array}$ & $\overline{\mathbf{N}^{\mathrm{a}}}$ & $\underset{b}{\text { Mean }}$ & $\begin{array}{l}\text { Median } \\
\text { (IQR) }\end{array}$ & Range & $\begin{array}{l}\#> \\
1.0\end{array}$ \\
\hline 0 days & 27 & $2.29(0.08)$ & $\begin{array}{l}2.40 \\
(0.05)\end{array}$ & $\begin{array}{l}2.25 \text { to } \\
2.5\end{array}$ & 0 & 27 & 0.14 & $0.20(0.32)$ & $\begin{array}{l}0.01 \text { to } \\
0.69\end{array}$ & 0 \\
\hline 2 days & 13 & $2.31(0.09)$ & $\begin{array}{l}2.43 \\
(0.07)\end{array}$ & $\begin{array}{l}2.27 \text { to } \\
2.51\end{array}$ & 0 & - & - & - & - & - \\
\hline 4 days & 13 & $2.30(0.08)$ & $\begin{array}{l}2.43 \\
(0.06)\end{array}$ & $\begin{array}{l}2.32 \text { to } \\
2.56\end{array}$ & 0 & - & - & - & - & - \\
\hline $\begin{array}{l}\text { 2nd to 4th week (days } 7 \text { to } \\
\text { 27) }\end{array}$ & 27 & $2.30(0.10)$ & $\begin{array}{l}2.43 \\
(0.09)^{c}\end{array}$ & $\begin{array}{l}2.24 \text { to } \\
2.57\end{array}$ & 0 & 33 & $0.33^{d}$ & $0.31(0.31)$ & $\begin{array}{l}0.06 \text { to } \\
1.05\end{array}$ & 3 \\
\hline $\begin{array}{l}\text { 5th to 8th week (days } 28 \text { to } \\
55 \text { ) }\end{array}$ & 20 & $2.29(0.07)$ & $\begin{array}{l}2.43 \\
(0.05)\end{array}$ & $\begin{array}{l}2.34 \text { to } \\
2.51\end{array}$ & 0 & 35 & $0.31^{d}$ & $0.41(0.31)$ & $\begin{array}{l}0.05 \text { to } \\
1.48\end{array}$ & 4 \\
\hline $\begin{array}{l}\text { 9th to } 11 \text { th week (days } 56 \text { to } \\
\text { 76) }\end{array}$ & 14 & $2.39(0.11)$ & $\begin{array}{l}2.46 \\
(0.06)\end{array}$ & $\begin{array}{l}2.37 \text { to } \\
2.61\end{array}$ & 1 & 28 & $0.33^{d}$ & $0.36(0.36)$ & 0 to 1.74 & 2 \\
\hline \multirow[t]{2}{*}{ Total } & 114 & $2.31(0.09)$ & $\begin{array}{l}2.42 \\
(0.07)\end{array}$ & $\begin{array}{l}2.24 \text { to } \\
2.61\end{array}$ & 1 & 123 & 0.24 & $0.33(0.36)$ & 0 to 1.74 & 9 \\
\hline & $N$ & Mean (SD) & $\begin{array}{l}\text { Mean } \\
\text { (SD) }\end{array}$ & Range & $\begin{array}{l}\#> \\
3.00\end{array}$ & & & & & \\
\hline Cord Blood & 12 & $2.57(0.23)$ & $\begin{array}{l}2.68 \\
(0.16)\end{array}$ & $\begin{array}{l}2.28 \text { to } \\
2.9\end{array}$ & 0 & - & - & - & - & - \\
\hline
\end{tabular}

\footnotetext{
a. Number of specimens (there may have been multiple specimens from a single participant during a given follow-up period).

b. Geometric means.

c. Mean at day 7 was higher than baseline $(+0.05 ; 95 \% \mathrm{Cl}, 0.01$ to 0.08$)$, which remained statistically significant after correcting for multiple testing

d. Means at days 7, 14, 21, 28, 35, 56, and 63 were significantly higher than baseline, after correcting for multiple testing.
} 


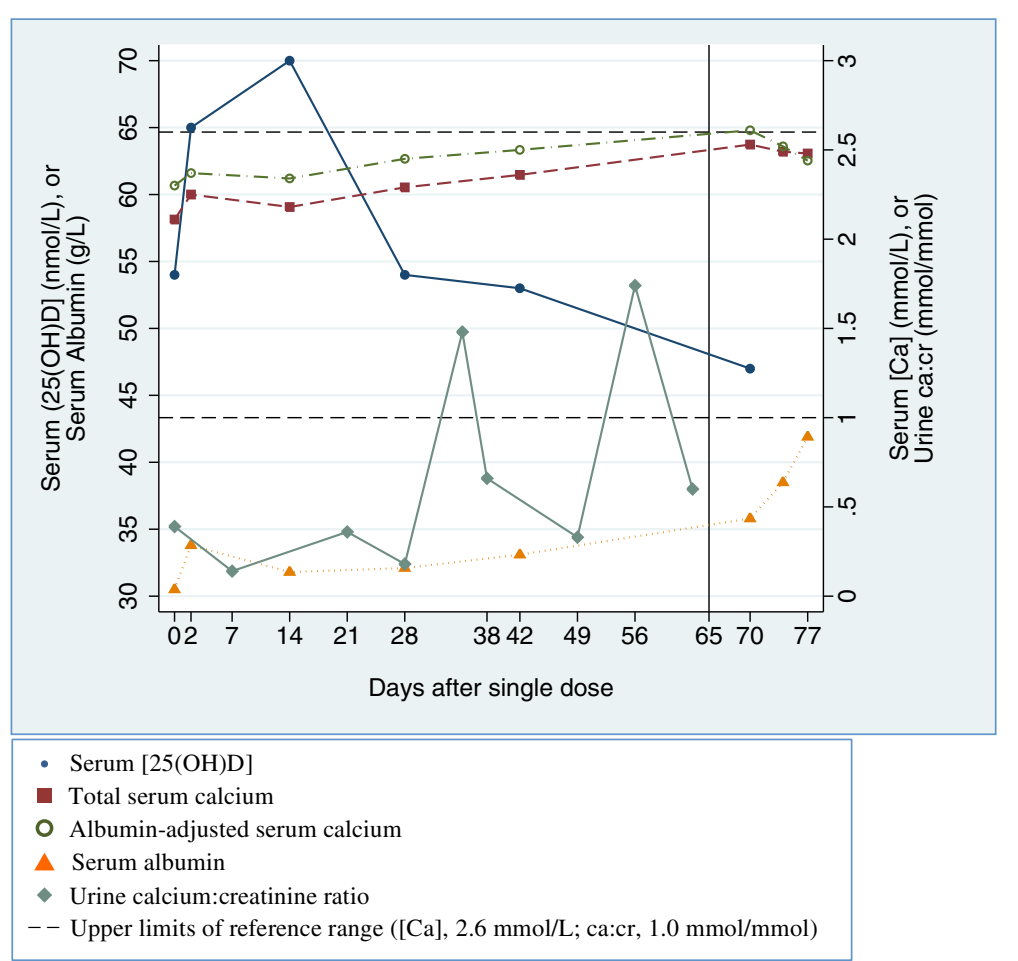

Figure 6 Serum and urine biochemistry in a pregnant participant with two episodes of urine ca:cr $>1.0 \mathrm{mmol} / \mathrm{mmol}$ and one episode of serum albumin-adjusted [Ca] $>\mathbf{2 . 6 0} \mathbf{~ m m o l} / \mathbf{L}$. Vertical line indicates timing of delivery at 39 weeks gestation.

demonstrated that the administration of a single dose of 600,000 IU to healthy young adults caused an increase in serum $[\mathrm{Ca}]$ at 3 days, coinciding with peak serum concentrations of both $25(\mathrm{OH}) \mathrm{D}$ and the active metabolite, 1,25-dihydroxyvitamin D (1,25(OH)2D) [20]. Therefore, upward deflections in the serum and urine biomarkers of calcium homeostasis signaled a need to be cautious about the transient effects of large sudden influxes of vitamin D, and the risk of dose-dependent toxicity.

There were several limitations of this study. First, although we were able to closely monitor the participants to gain preliminary PK and safety data in this population, the small sample size limited the precision of effect estimates and comparisons of non-pregnant and pregnant participants. Moreover, we did not have adequate power to adjust for differences in the baseline characteristics of the pregnant and non-pregnant groups, although we did not expect minor variations in age or socioeconomic status to influence biochemical responses. Second, the low number of scheduled blood specimens collected from each individual compromised the precision of the estimates of individual-level PK parameters. The number was limited by available funds and the expected acceptability of the procedure by participants based on prestudy consultation with local community members. Third, the fixed timing of specimen collection had the disadvantage of leaving gaps in the $[25(\mathrm{OH}) \mathrm{D}]$-time curve where no data were available. Fourth, the study lacked an unsupplemented control group. The analysis was challenged by the substantial inter-individual variability in responses to supplementation, which was expected based on previous reports [28]. Several participants had fluctuating $[25(\mathrm{OH}) \mathrm{D}]$, without a single clear peak and decline, and some manifested seemingly paradoxical responses, with initial declines in [25(OH)D] after D3 ingestion. These erratic patterns could not easily be explained on the basis of known vitamin $D$ pharmacokinetics, but were most likely attributable to small-sample artifacts, biological variability in the absorption and metabolism of vitamin $\mathrm{D}$, and inherent imprecision in the laboratory assessment of $[25(\mathrm{OH})$ D]. Nonetheless, the data yielded coherent populationaveraged interpretations that were consistent with published data from non-pregnant adults in other settings.

\section{Conclusions}

Comparisons of pregnant (third-trimester) to non-pregnant participants, as well as comparisons to previously published PK studies in non-pregnant adults, suggested that the effects of pregnancy on the $25(\mathrm{OH}) \mathrm{D}$ response to vitamin D3 were relatively minor and did not substantially impact overall bioavailability. Likewise, we did not document any notable pregnancy-related hypersensitivity to a vitamin $\mathrm{D}$ dose of 70,000 IU in terms of its effects on calcium 
homeostasis. However, the unpredictability of the $25(\mathrm{OH}) \mathrm{D}$ response at the individual level, previous reports of adverse effects of large single doses [23], and the theoretical disadvantages of excessive fluctuations in vitamin D status [29] suggest that the use of large single or infrequent intermittent doses of vitamin D3 may be physiologically disadvantageous despite its practical appeal. Therefore, these data principally support the further investigation of single doses equal to or less than 70,000 IU in the context of intermittent (e.g., weekly or biweekly) antenatal dosing regimens.

\begin{abstract}
Abbreviations
PK: Pharmacokinetics; [25(OH)D]: 25-hydroxyvitamin D concentration; $\Delta[25$ $(\mathrm{OH}) \mathrm{D}]$ : Change in [25(OH)D] from baseline; [Ca]: Albumin-adjusted serum calcium concentration; ca:cr: Urinary calcium:creatinine ratio; Cmax: Maximum observed [25(OH)D]; $\Delta$ Cmax: Maximum observed $\Delta[25(\mathrm{OH})$ D] above baseline; Tmax: Timing of Cmax; $\Delta$ Cavg $_{28}$ : Average $\Delta[25(\mathrm{OH}) \mathrm{D}]$ during the first 28 days after dose administration; AUC: Area under the $\Delta[25$ $(\mathrm{OH}) \mathrm{D}$ ]-time curve; $A \cup C_{28 / 35}$ : AUC calculated for 0 to 28 days or 0 to 35 days, depending on the timing of the blood sampling; $A \cup C_{56 / 70}$ : AUC for the period 0 to 56 days or 0 to 70 days; GEE: Generalized estimating equations.
\end{abstract}

\section{Competing interests}

The authors declare that they have no competing interests.

\section{Authors' contributions}

All authors were involved in the design of the study; DR and AM conducted the research; RR coordinated the laboratory analyses; DR performed the statistical analysis, wrote the manuscript, and had primary responsibility for the final content. All authors read and approved the final manuscript.

\section{Acknowledgements}

We appreciate the efforts of the following individuals: staff at ICDDR,B and Shimantik who supported and implemented the study, including Taufiq Rahman, Sultana Mahabbat-e Khoda, Evana Akhtar, Eliza Roy, Ashish Chowdhury, and Kazi Moksedur Rahman; Reinhold Vieth (Mount Sinai Hospital, Toronto) for performing the measurement of 25-hydroxyvitamin D concentrations and verifying the concentration of the vitamin D3 supplement; Brendon Pezzack for assistance with manuscript preparation. Thank you to Diasorin Inc. (Stillwater, MN) for donating the kits used in the Liaison Total assay, and to Popular Pharmaceuticals Inc. (Dhaka, Bangladesh) for supplying the Vigantol Oil.

Research was supported by funding from the Center for Global Health, Johns Hopkins University (A. Baqui) and the Department of International Health at The Johns Hopkins Bloomberg School of Public Health (R. Black). D. Roth was supported by training awards from The Alberta Heritage Foundation for Medical Research and The Canadian Institutes of Health Research. Sponsors did not have any role in study design, data collection, data analysis, data interpretation, writing of the manuscript, or the decision to submit the manuscript for publication.

\section{Author details \\ ${ }^{1}$ Department of International Health, The Johns Hopkins Bloomberg School of Public Health, Baltimore, MD 21205, USA. ${ }^{2}$ International Center for Diarrhoeal Disease Research, Bangladesh (icddr,b), Dhaka, Bangladesh. ${ }^{3}$ Current address: Department of Paediatrics, Hospital for Sick Children and University of Toronto, Toronto, ON, Canada.}

Received: 10 April 2012 Accepted: 21 December 2012 Published: 27 December 2012

\section{References}

1. Ross AC, Taylor CL, Yaktine AL, Del Valle HB: Committee to Review Dietary Reference Intakes for Vitamin D and Calcium, Institute of Medicine. Dietary Reference Intakes for Calcium and Vitamin D. Washington, DC: The National Academies Press; 2010.

2. ACOG Committee Opinion No. 495: Vitamin D: screening and supplementation during pregnancy. Obstet Gynecol 2011, 118:197-198.
3. Specker BL: Does vitamin D during pregnancy impact offspring growth and bone? Proc Nutr Soc 2011, FirstView:1-8.

4. Roth DE: Vitamin D, supplementation during pregnancy: safety considerations in the design and interpretation of clinical trials. J Perinatol 2011, 31:449-459.

5. Sahu M, Das V, Aggarwal A, Rawat V, Saxena P, Bhatia V: Vitamin D replacement in pregnant women in rural north India: a pilot study. Eur J Clin Nutr 2009, 63:1157-1159.

6. Zeghoud F, Garabedian M, Jardel A, Bernard N, Melchior J: Administration of a single dose of 100,000 U.I. of vitamin D3 in the pregnant woman in winter. The effect on blood calcium level of the newborn infant. J Gynecol Obstet Biol Reprod (Paris) 1988, 17:1099-1105.

7. Marwahaa RK, Tandona N, Chopraa S, Agarwala NM, Garga K, Sharmaa B, Kanwara RS, Bhadraa K, Singha S, et al: Vitamin D status in pregnant Indian women across trimesters and different seasons and its correlation with neonatal serum 25-hydroxyvitamin D levels. Br J Nutr 2011, 106:1383-1389.

8. Roth DE, Shah MR, Black RE, Baqui AH: Vitamin D status of infants in northeastern rural bangladesh: preliminary observations and a review of potential determinants. J Health Popul Nutr 2010, 28:458-469.

9. Seamans KM, Cashman KD: Existing and potentially novel functional markers of vitamin D status: a systematic review. Am J Clin Nutr 2009, 89:1997S-2008S.

10. Armas LA, Hollis BW, Heaney RP: Vitamin D2 is much less effective than vitamin D3 in humans. J Clin Endocrinol Metab 2004, 89:5387-5391.

11. Ilahi M, Armas LA, Heaney RP: Pharmacokinetics of a single, large dose of cholecalciferol. Am J Clin Nutr 2008, 87:688-691.

12. Maalouf J, Nabulsi M, Vieth R, Kimball S, El-Rassi R, Mahfoud Z, El-Haj, Fuleihan G: Short- and long-term safety of weekly high-dose vitamin D3 supplementation in school children. J Clin Endocrinol Metab 2008, 93:2693-2701.

13. Wagner $\mathrm{D}$, Hanwell HE, Vieth $\mathrm{R}$ : An evaluation of automated methods for measurement of serum 25-hydroxyvitamin D. Clin Biochem 2009, 42:1549-1556.

14. Carter GD, Berry JL, Gunter E, Jones G, Jones JC, Makin HL, Sufi S, Wheeler MJ: Proficiency testing of 25-hydroxyvitamin D (25-OHD) assays. J Steroid Biochem Mol Biol 2010, 121:176-179.

15. Standing Committee on the Scientific Evaluation of Dietary Reference Intakes: Food and Nutrition Board IOM. In Dietary Reference Intakes for Calcium, Phosphorus, Magnesium, Vitamin D, and Fluoride. Edited by DRI. Washington: National Academy Press; 1997.

16. Vieth R, Chan PC, MacFarlane GD: Efficacy and safety of vitamin D3 intake exceeding the lowest observed adverse effect level. Am J Clin Nutr 2001, 73:288-294.

17. Gordon AY, Salzman P: Optimality of the Holm procedure among general step-down multiple testing procedures. Stat Probability Lett 2008, 78:1878-1884

18. Payne RB, Little AJ, Evans RT: Albumin-adjusted calcium concentration in serum increases during normal pregnancy. Clin Chem 1990, 36:142-144.

19. Romagnoli E, Mascia ML, Cipriani C, Fassino V, Mazzei F, D’Erasmo E, Carnevale V, Scillitani A, Minisola S: Short and long-term variations in serum calciotropic hormones after a single very large dose of ergocalciferol (vitamin D2) or cholecalciferol (vitamin D3) in the elderly. J Clin Endocrinol Metab 2008, 93:3015-3020.

20. Cipriani C, Romagnoli E, Scillitani A, Chiodini I, Clerico R, Carnevale V, Mascia ML, Battista C, Viti R, et al: Effect of a single oral dose of $600,000 \mathrm{IU}$ of cholecalciferol on serum calciotropic hormones in young subjects with vitamin D deficiency: a prospective intervention study. J Clin Endocrinol Metabol 2010, 95:4771-4777.

21. Bacon CJ, Gamble GD, Horne AM, Scott MA, Reid IR: High-dose oral vitamin D3 supplementation in the elderly. Osteoporos Int 2009, 20:1407-1415.

22. Weisman Y, Schen RJ, Eisenberg Z, Amarilio N, Graff E, Edelstein-Singer M, Goldray D, Harell A: Single oral high-dose vitamin D3 prophylaxis in the elderly. J Am Geriatr Soc 1986, 34:515-518.

23. Sanders KM, Stuart AL, Williamson EJ, Simpson JA, Kotowicz MA, Young D, Nicholson GC: Annual high-dose oral vitamin D and falls and fractures in older women: a randomized controlled trial. JAMA 2010, 303:1815-1822.

24. Hollis BW, Johnson D, Hulsey TC, Ebeling M, Wagner CL: Vitamin D supplementation during pregnancy: Double blind, randomized clinical trial of safety and effectiveness. J Bone Miner Res 2011, 26:2341-2357. 
25. Vähävihu K, Ylianttila L, Kautiainen $\mathrm{H}$, Viljakainen $\mathrm{H}$, Lamberg-Allardt C, Hasan T, Tuohimaa P, Reunala T, Snellman E: Narrowband ultraviolet B course improves vitamin $\mathrm{D}$ balance in women in winter. $\mathrm{Br} J$ Dermatol 2010, 162:848-853.

26. Bouillon R, Van Assche FA, Van Baelen H, Heyns W, De Moor P: Influence of the vitamin D-binding protein on the serum concentration of 1,25dihydroxyvitamin D3. Significance of the free 1,25-dihydroxyvitamin D3 concentration. J Clin Invest 1981, 67:589-596.

27. Haddad JG, Matsuoka LY, Hollis BW, Hu YZ, Wortsman J: Human plasma transport of vitamin D after its endogenous synthesis. J Clin Invest 1993, 91:2552-2555.

28. Heaney RP: Vitamin D, and calcium interactions: functional outcomes. Am J Clin Nutr 2008, 88:541S-544S.

29. Vieth R: How to optimize vitamin D supplementation to prevent cancer, based on cellular adaptation and hydroxylase enzymology. Anticancer Res 2009, 29:3675-3684.

doi:10.1186/1475-2891-11-114

Cite this article as: Roth et al: Pharmacokinetics of a single oral dose of vitamin D3 (70,000 IU) in pregnant and non-pregnant women. Nutrition Journal 2012 11:114.

\section{Submit your next manuscript to BioMed Central and take full advantage of:}

- Convenient online submission

- Thorough peer review

- No space constraints or color figure charges

- Immediate publication on acceptance

- Inclusion in PubMed, CAS, Scopus and Google Scholar

- Research which is freely available for redistribution 